\title{
A New Type of the Permanent Pancreatic Fistula. Permitting the Regulation of the Outflow of the Secretion.*)
}

\author{
By \\ W. N. Boldyreff, M.D., and O. E. Thompson, M. D. \\ (Pavlov Physiological Institute of the Battle Creek Sanitarium, \\ Battle Creek, Michigan, U.S.A.)
}

\section{Introduction.}

Pancreatic fistula is one of the most important operations in the physiological surgery of the digestive apparatus.

Many pages have been devoted by physiologists to descriptions of this operation and the properties of the pancreatic juice obtained with various types of operation. One of us (Boldyreff) has several times published articles on this subject ${ }^{1,2)}$ as well as on the significance for the organism of the loss of pancreatic juice. ${ }^{3)}$

In a report together with Dr. W.F. Martin, ${ }^{2)}$ Boldyreff makes a comparison of advantages of various methods for this operation and sums up a short history of it.

We do not at this time enter into such details, but dwell briefly on some of the most interesting aspects of this problem.

The pancreatic fistula was first offered almost three hundred years ago (Regner de Graaf, 1664); but up to the present we have had no method of operation which would enable us to maintain the fistular animal in the normal state. Such a method is described in the paper presented.

The classical Heidenhain-Pavlovi) operation for the permanent pancreatic fistula has the handicap that large amounts of pancreatic juice are continually escaping through it. This renders the ani-

*) Reported April 15, 1940, at the Annual Meeting of the American Physiological Society, at New Orleans, La.

Compare to W. N. Boldyreff, and W. F. Martin: Tohoku Jour. Exper. Med, $1939,35,144$. 
mals pathologic, even in the early days (Pancreatic triad, W. N. Boldyreff ${ }^{3)}$ ) and sometimes they die from this cause two or three weeks after the operation (due to pancreatic hypersecretion). All such animals are doomed to death at the end of about a year.

Ivy's method ${ }^{5)}$ is free from this defect, but it does not permit the collection of all the juice secreted by the pancreas, but only a portion of it.

In order to limit possible loss of juice, $\mathrm{Pav}$ lov attempted to make his operation not on the main but on the small pancreatic duct. But the operation for such a fistula is very difficult technically and it furnishes very little juice. For this reason this fistula was given up. It comes near Ivy's fistula in the amount of juice secreted but Ivy's operation is easy and supplies zymogen juice, whereas $\mathrm{Pavlov's} \mathrm{sup-}$ plies the active juice.

Boldyreff and Martin have recently published a description of their method for a permanent closeable pancreatic fistula, free from the defects mentioned. The weak point of this method is that when the fistula is closed for some time, there is a possibility that the gland may degenerate. Also dogs with a permanent closeable pancreatic fistula require a great deal of care.

Our new operation consists of combining the usual duodenal fistula made in the proper place with a special kind of pancreatic fistu1a. The first procedure is well known and requires no description. The second part of the operation consists of insertion of a glass cannula into the main (or small) pancreatic duct from the inside of the intestine through the natural orifice. This glass cannula is kept in place by a strong ligature and is tightly tied on its neck on the outside of the pancreatic duct.*) A rubber tube about eight inches long is put on the free end of the glass cannula. A string is attached to the end of the rubber tube allowing it to be pulled outside through the tube of the duodenal fistula.

Outside of experiments the rubber tube lies in the intestine; the pancreatic juice (or bile) flows freely into the intestine, takes part in digestion and is then absorbed. During the experiment the end of the rubber tube is drawn outside and one can collect pure juice from

*) Instead of the pancreatic duct one may tie the glass cannula into the ductus choledochns (which is even simpler) and then we will have a normal animal with the bile fistula. Naturally, other parts of the operation for the pancreatic fistula and the bile fistula will be almost the same. It is also possible to make both fistulae, the pancreatic and the biliary, either at once or at different times, on the same animal. 
it. The rubber and the string are then concealed inside the fistular duodenal tube. The end of the string hangs outside and is covered with a special cap which fits into the rim of the duodenal tube (See Fig. 1 and 2).

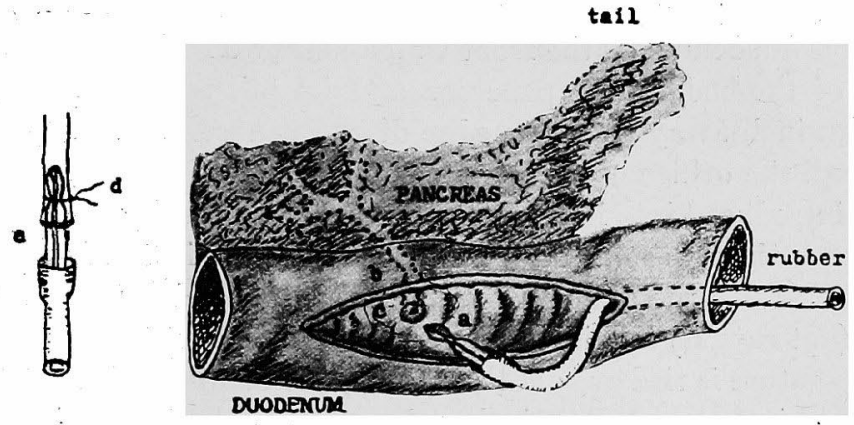

- Fig. 1. Beginning of the operation.

a-glass cannula. $\quad b$-main duct. $\quad c$-orifice of the duct. d-suture holding the cannula in the duct.

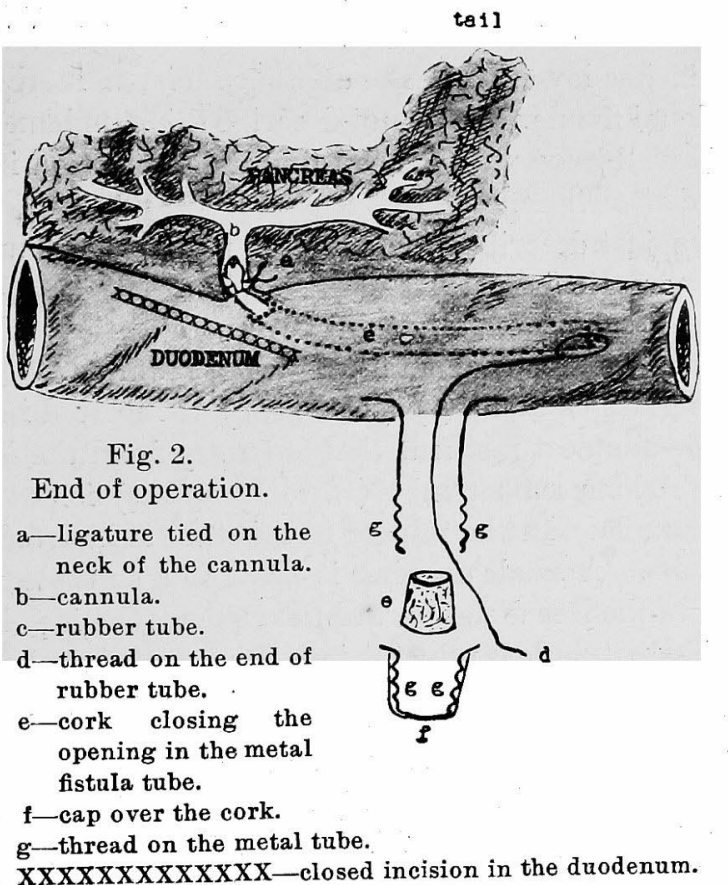




\section{Description of the Operation.}

An incision is made in the skin and deeper along the linea alba from the ensiform cartilage downward, about five to six inches. The duodenum and pancreas are drawn outside. An incision is then made along the duodenum on the front wall about two inches long, from the corner of the body of the pancreas and its tail toward the stomach $3 / 4$ of an inch away from the edge of the pancreas. The duodenum is opened, the orifice of the main pancreatic duct is found, and a cannula is introduced into it. (See Fig. 1.) This is easily accomplished, but in case there is some difficulty, a metal sound is first inserted into the duct. With the aid of a needle, or a fine bend forceps, a strong suture (not catgut) is laid under the main duct next to the duodenum and this suture is tied around the neck of the cannula which has been introduced into the pancreatic duct from inside the intestine. A rubber tube is put on the free end of the cannula, and a strong thread is attached to the outer end of this tube, which is about seven or eight inches long, and the thread about the same length. The rubber is firmly tied around the end of the cannula. The rubber and the cannula are concealed in the intestine. The duodenal incision is closed. About two inches lower we make another incision in the duodenum for the duodenal fistula. We do not describe this supplementary operation, as it is well known. One can find its description in Pavlov's works ${ }^{4,6)}$ and elsewhere. ${ }^{1)}$

We have just described the simplest method for our new operation for a pancreatic fistula.

We have also successfully tried two modifications of this operation; in both cases the duodenal fistula is not required.

I. The glass cannula (a) (see Fig. 3) is inserted into the main duct as in the simplest method, that is to say from the inside of the duodenum. A long rubber tube (12 to 15 inches) is put on the frepe end of the cannula. In the middle of this tube is-inserted a T-shaped bent glass tube. A small opening is made in a suitable place in the duodenum and the free distal part of the rubber tube is pulled through it until the T-shaped glass tube fits into this opening. A purse-string suture is laid around it along the edge of the opening in the duodenum and tightly tied around the glass (see Fig. 3).

The distal part of the rubber tube is led outside from the abdominal cavity and is placed under the skin. The skin incision is closed over it. A short glass stopper is inserted into the free end of the rub- 


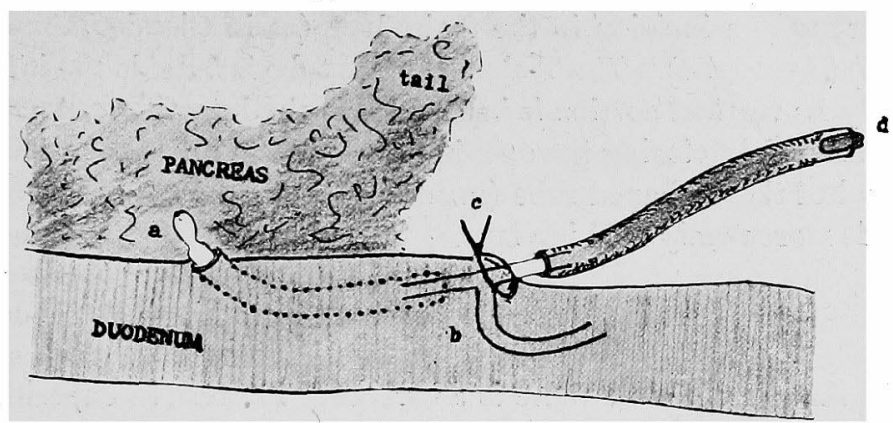

Fig. 3. First modification of the same operation.

a-cannula. b-T-shaped tube.

c-supporting suture, holding the tube in place in the duodenum.

d-glass stopper.

ber tube, closing it as a cork in a bottle. When the wound heals, one can insert the needle of a syringe into the rubber tube, feeling it through the skin, and obtain some pancreatic juice. The juice usually flows through the cannula along the proximal portion of the rubber tube and further through the vertical T-shaped tube into the intestine. When the needle of a syringe is inserted into the distal part some portion of the juice flows outside.

II. This is almost the same as the method just described, but the glass cannula is inserted not from inside the duodenum, but outside

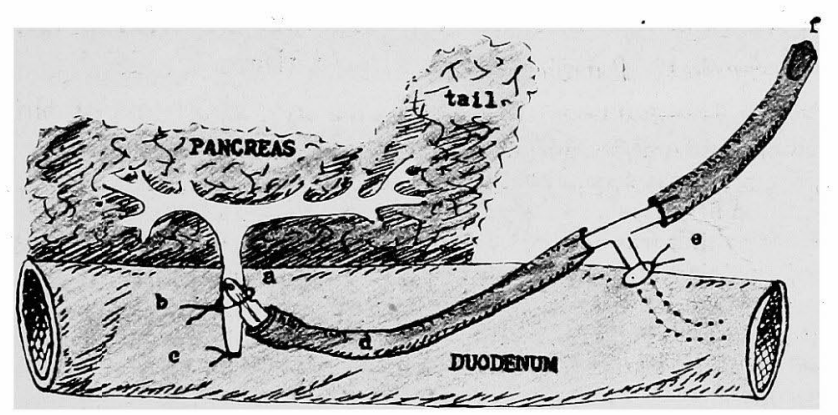

Fig. 4. Second modification.

a-cannula.

b-suture holding the cannula in the duct.

c-suture on main duct close to the orifice.

d-rubber tube.

e-suture supporting.T-shaped tube.

f-glass stopper. 
of it through an incision in the main duct (as in Claude Bernard's method) (See Fig. 4). The T-shaped glass tube is outside the intestine and only its vertical portion is inserted into the intestine. A ligature is tied around it, closing the opening made in the intestine. The vertical end of the T-shaped tube (inside the intestine) should be bent so that it is more firmly held in place.*)

\section{Discussion.}

At the present time there is a revival of interest in experimental work on the physiology of the pancreas. We may mention Northrop's crystalline trypsin ${ }^{7)}$ and experiments of Rocha e Silva $a^{8)}$ which prove that addition of trypsin to the liquid circulating through the blood vessels of an isolated organ increase its capacity for work. Trypsin also plays an important role in blood coagulation (A. Boldyreff, ${ }^{9)}$ Eagle and Harri s $\left.{ }^{10}\right)$. Its addition to the hemophilian blood increases its coagulability (Tyson and West ${ }^{11}$ ). We consider all these accomplishments very important; aside from their purely scientific value they may find a wide and useful application in clinical medicine.**)

If one does not take into account the discovery of insulin and the works of Minkowski and those of Zuelzer which preceded it, as well as findings of Pavlov's school, and others in digestive work of the pancreas one may conclude that the physiology of this gland has advanced little, since the time of the famous experiments of Regner de Graaf, that is to say, during almost three hundred years. The

) These operations were made on dogs. Six animals were operated in the first method and eight in the second and third methods altogether. All these animals survived, except the first three. One was killed immediately after the operation in order to see how everything was accomplished; two died of peritonitis, having been operated upon by insufficiently trained students, who made surgical blunders.

H) Participation of trypsin in the coagulation of blood was first indicated by our laboratory in 1926 in Paris at the Societe de Biologie and at Stockholm at the XIIth International Physiological Congress and published in the proceedings of both these conferences.

Our further experiments on this function of the pancreas are to be found in the article "The pancreatic triad" published in three American journals in 1928 and 1929 and in the Ergebnisse d. Physiologie in 1925 and 1929. ${ }^{11}$ )

Altogether, our experiments were described in seven most popular jonrnals of Europe and America and elsewhere (see proceedings of Messina Academy, 1939).

Unfortunately, Dr. No'rth rop in his book does not refer to our work. We recall also that some time ago we supplied him with some pancreatic juice from our experimental dogs. 
main reason for this is the fact that this organ is extremely delicate and its function is particularly complex. On the other hand, the pancreas is an important organ both in the work of digestion and in internal secretion (metabolism) it carries the main responsibility. One may hope that this state of affairs may now soon radically improve. Some outstanding diseoveries have been made during the last few years in America (insulin, crystalline trypsin, etc.).

Possibly the new operation we are offering may attract more attention at this time when there is a revival of interest in the work on physiology of the pancreas; for our operation allows us to regulate the flow of pancreatic juice much as we can control the flow of water from a tap. We open the tap (our fistula), and water flows out; we close the tap (in our case the pancreatic fistula), and the water (that is the pancreatic juice) is kept inside.

Now one can operate successfully on such large and costly animals as horses in order to secure larger amounts of pancreatic juice which was formerly impossible because animals with pancreatic fistulae were threatened with a quick and inevitable death.

\section{Conclusion.}

Our operation radically differes from all other types of pancreatic fistula in the following details :

1. The cannula is inserted into the duct, not through an artificial opening, but through a natural orifice from inside the duodenum.

2. The cannula and the rubber tube put on its free end are permanently left in the duodenum where the pancreatic juice (or bile if the cannula is inserted into the bile duct) flows out just as before the operation. There is no disturbance of the normal flow of this juice into the intestine.

3. When we wish to collect pancreatic juice, the end of this rubber tube is drawn out by the thread which was attached to it. Then this end of the rubber tube is pulled out through the metal tube of the duodenal fistula, which is inserted into the duodenum during the operation for the pancreatic fistula after our method.

4. Comparing this method with the classical operation for the pancreatic fistula after Pavlov we see that whereas in his method pancreatic juice always flows outside and this makes the animal ill immediately after the operation and eventually kills him, in our case the juice flows outside only when we want it, which is comparatively 
rarely. A large portion of the juice enters the intestine, as before the operation, takes part in the work of digestion and is absorbed. The animal remains perfectly normal after the operation.

5. Our operative technique is much more simple than Pavlov's as we find the orifice of the duct as soon as we dissect the intestine. The supplementary operation for the duodenal fistula is so elementary that it does not complicate the main operation for the surgeon and does not make it much more difficult for the animal operated upon; it remains normal.

6. After operation, healing of the wound is usually by first intention. In Pavlov's method of operation the edges of the incision often come open being digested by the active pancreatic juice which flows there after the operation. This may even cause a perforation in the abdominal wall, followed by peritonitis and death.

7. After our operation we obtain zymogen juice perfectly pure, whereas in Pavlov's method the pancreatic juice is contaminated by the ad-mixture of intestinal juice. It is also slightly soiled by flowing over the skin, which may become abnormal from constant moistening, with the result that it ulcerates and breaks, the exudation further contaminating the juice. In Pavlov's fistula one can, of course, insert the cannula for collection of the juice through the orifice, so that it remains perfectly pure, but this is often rather cumbersome.

8. Such fistula may serve for collection of bile, when the cannula is inserted into the bile duct. And even two fistulae, the pancreatic and the bile, may be made on the same animal which is impossible in other methods.

9. The method described has another advantage. The glass can- . nula can be removed from the main pancreatic duct any time after the operation (the same is true for the metal tube in the duodenum, if necessary).

Our cordial thanks to Mr. H. F. Simonds for kind and efficient assistance in this work.

\section{REFERENCES.}

(1) Boldyreff, W. N. Surgical method in the physiology of digestion. Description of the most important operations on the digestive system. Bull. B. C. San. \& Hosp. Clinic, 1925, 20, 206; Erg. d. Physiol., 1925, 24, 399.

(2) Boldyreff, W. N. and Martin, W. F. The operation for and the importance of a permanent closeable pancreatic fistula, Tohoku Jour. Exp. Med., 1939, 35, 144. 
(3) Body reff, W. N. The pancreatic triad. Am. Jour. Med. Sci, 1929, 177, 778; Bull. B. C. San. \& Hosp. Clin., 1929, 24, ; Am. Jour. Physiol., 1928, 85, 353.

(4) Pavlov, I. P. Die physiologische Chirurgie des Verdauungskanals. Erg. d. Physiol., 1902, 1(1), 246.

(5) Ivy, A. C. and Farrell, J.I. Contributions to the physiology of the pancreas. 1. A method for the subcutaneous anto-transplantation of the tail of the pancreas. Am. Jour. Physiol., 1926, 77, 474.

(6) Pavlov, I. P. Die operative Methodik des Studiums der Verdauungsdrüsen. Tigersted ts Handb. d. physiol. Method., 1911, 2(1), 150.

(7) Northrop, J.H. Crystalline enzymes. The chemistry of pepsin, tripsin and bacteriophage. Columbia University Press. 1939.

(8) Rocha e Silva, M. Farmacologia da tripsina. Acao sobre musculo liso e coraca isolado de maniferos. Ffeitós circulatorios da tripsina. Experiencias com uma preparacao cristalina. Arquivos do Inst. Biol., 1939, 10, 93.

Acao da tripsina sobre or intestino e utero isolados de bocais; libertacao de histamina do pulmao, pela perfusao com solucoes de tripsina. Arquivos do Inst. Biol., $1938,9,145$.

(8a) Bo dy reff, W. N. The surgical method. Erg. d. Physiol., 1925, 24, 438.

(9) Boldyreff, W. N. and Boldyreff, A. W. Le panereas source de fibrin ferment du sang. Comp. rend. Soc. Biol:, 1926, 95, 447; Skand. Arch. Physiol., 1926, 49, 96 (12. Internat. Physiol. Congr. Stockholm, 1926).

(9a) Boldyreff, W. N. L'attivita periodica del pancreas. Atti della Reale Accademia Peloritana, 1939, 16, 17.

(10) Boldy reff, W. N, Haemophilia. Tohoku Jour. Exp. Med., 1937, 31, 469.

(11) Bold y reff, W. N. Die periodisehe Tätigkeit des Organismus und ihre physiol. Bedeutung. Erg. d. Physiol., 1929, 29, 575.

(12) E a gle, H. and H a rris, T. N. Studies in blood coagulation. 5. The coagulation of blood by proteolytic enzymes (trypsin, papain). Jour. Gen. Physiol., 1937, 20, 543.

(13) Tyson, T. L. and West, R. Effect of trypsin on the clotting of the blood in hemophilia. Proc. Soc. Exp. Biol. \& Med., 1937, 36, 494. 